Supporting Information

\title{
Facile Preparation of Highly Transparent Conducting Nanopaper with Electrical Robustness
}

Kaili Zhang, ${ }^{a}$ Guangxue Chen, ${ }^{a b}$ Ren'ai Li, ${ }^{a}$ Kai Zhao, ${ }^{a}$ Jiachen Shen, ${ }^{a}$ Junfei Tian, ${ }^{a}$ Minghui He*a

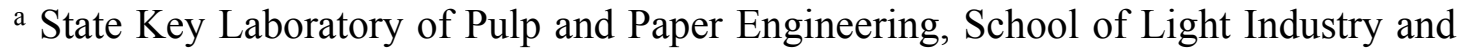
Engineering, South China University of Technology, Guangzhou 510640, China.

b Guangdong Engineering Research Center for Filtration and Wet Non-Woven Composites, Guangzhou 510640, China

*Corresponding author's E-mail: heminghui@scut.edu.cn

The supporting information included 9 pages, 10 figures, 4 tables and 1 formula. 


\section{Contents}

1. Figure S1. A picture of the CNF dispersion in water. (Page S3)

2. Figure S2. (a) TEM image of the CNF;(b) AFM image of the CNF on a mica substrate. (Page S3)

3. Figure S3. Cross-sectional SEM image of the nanopaper and the TCNP. (Page S3)

4. Figure S4. Schematic illustration (left) and photograph (right) of the details for measuring the conductivity of the TCNP. (Page S4)

5. Figure S5. A transparent PDES liquid (left) and the transparent solid poly(PDES) (right). (Page S4)

6. Figure S6. Transparent nanopaper. (Page S4)

7. Figure S7. The transmittance of transparent paper with a varying thickness at 550 nm. (Page S5)

8. Figure S8. Patternable printing of TCNP and personalized display of TCNP-based electroluminescent devices. PDES was used as conductive ink to print the (a) circle, (b) star and (c) butterfly on nanopaper by screen printing, and the electroluminescent devices (d-f) were assembled correspondingly. (Page S5)

9. Figure S9. Thermal gravimetric analysis (TGA) of the PDES and the TCNP. (Page S6)

10. Figure S10. Long-term electrical robustness of TCNP. The assembled electroluminescent devices even remained high brightness after 180 days. (Page S6)

11. Table S1. Average thickness of nanopaper with different gram weight. (Page S7)

12. Table S2. The weight of the nanopaper and the TCNP. (Page S7)

13. Table S3. The addition amounts of AgNWs, PEDOT:PSS, CNT and graphene. (Page S7)

14. Formula S1. The conductivity was calculated by the formula, C=R*S/L. (Page S7)

15. Table S4. Preparation and transparency of transparent conducting nanopaper with common conductive materials. (Page S8) 


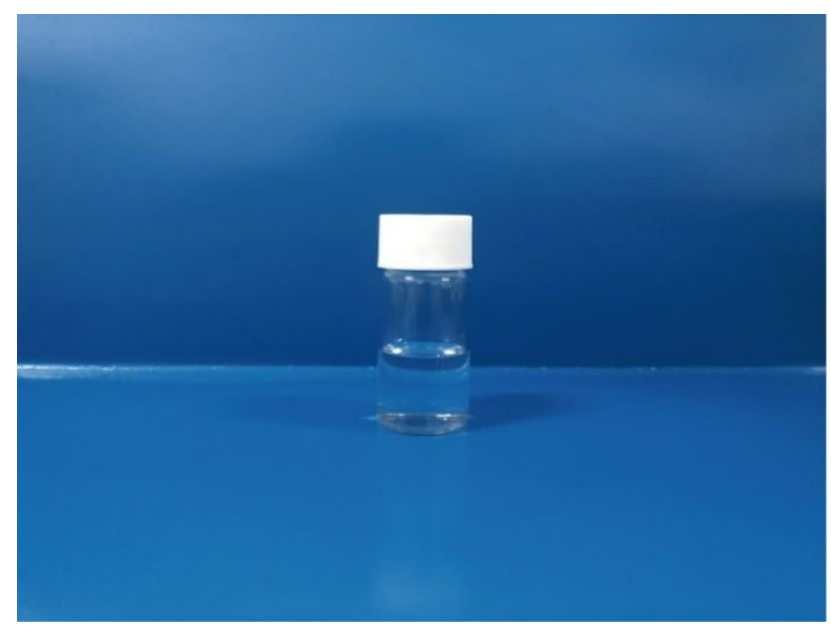

Figure S1. A picture of the CNF dispersion in water.
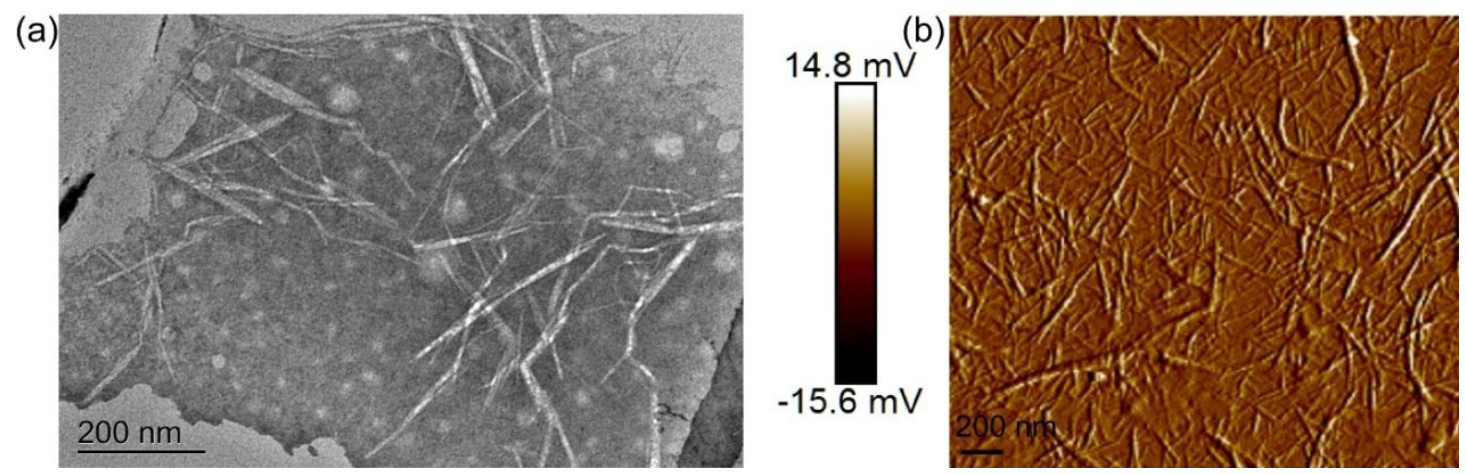

Figure S2. (a) TEM image of the CNF; (b) AFM image of the CNF on a mica substrate.

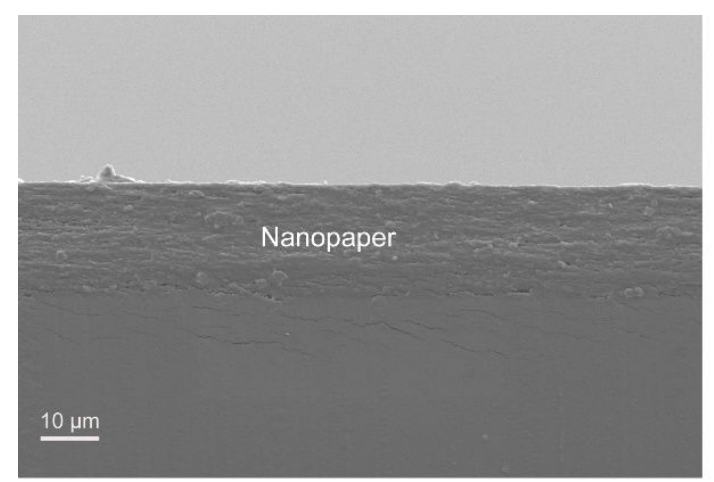

Nanopaper

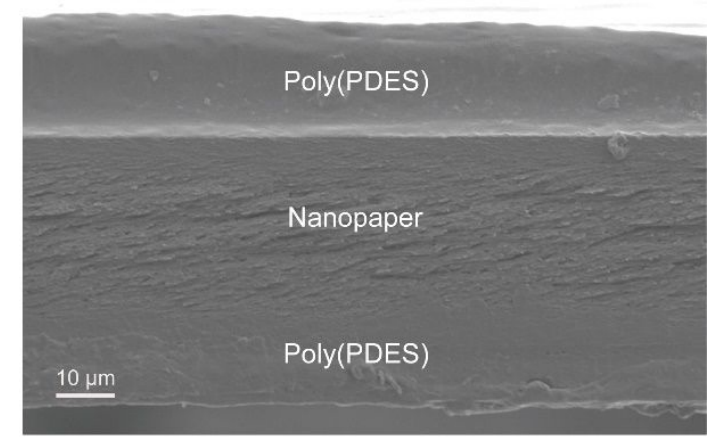

TCNP

Figure S3. Cross-sectional SEM image of the nanopaper and the TCNP. 

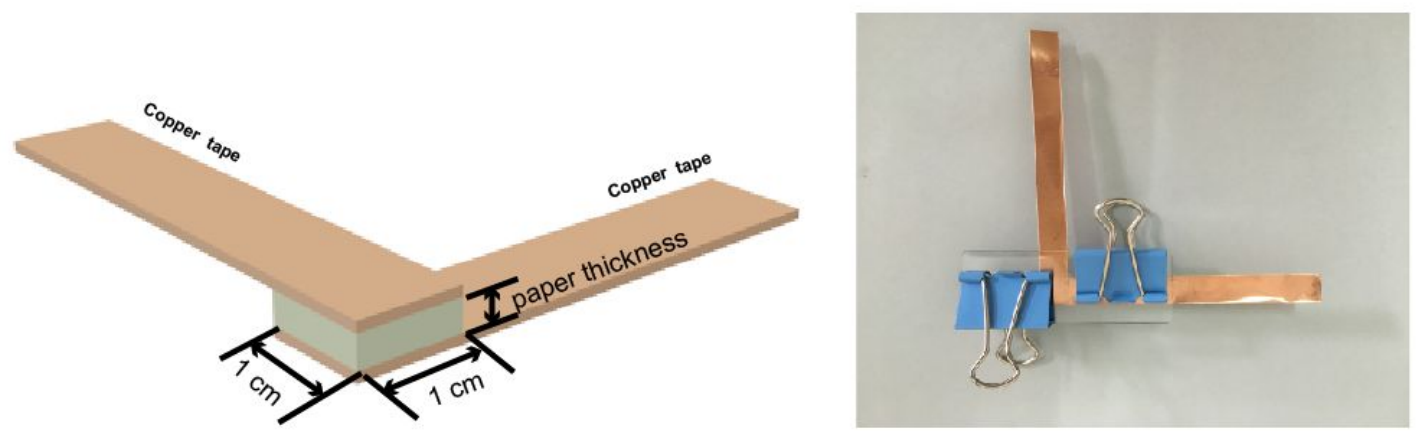

Figure S4. Schematic illustration (left) and photograph (right) of the details for measuring the conductivity of the TCNP.

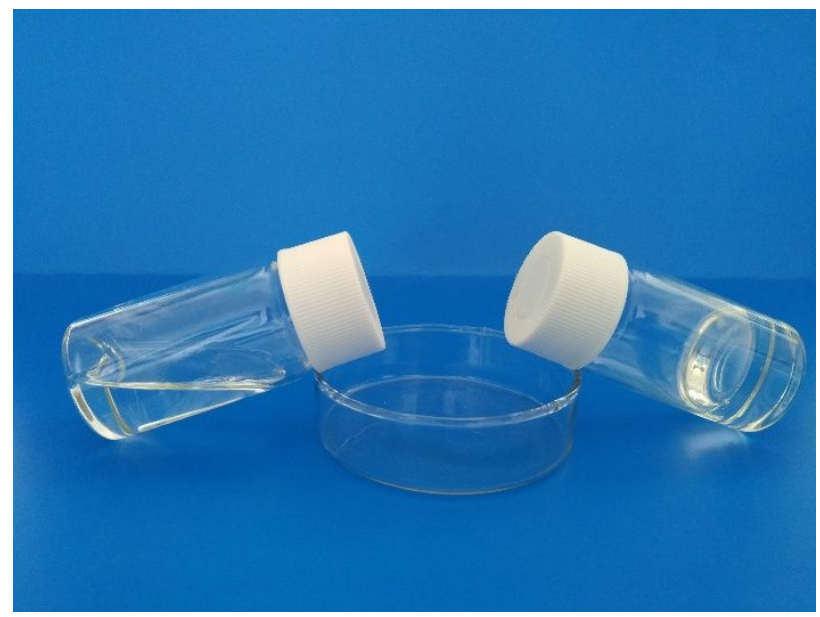

Figure S5. A transparent PDES liquid (left) and the transparent solid poly(PDES) (right).

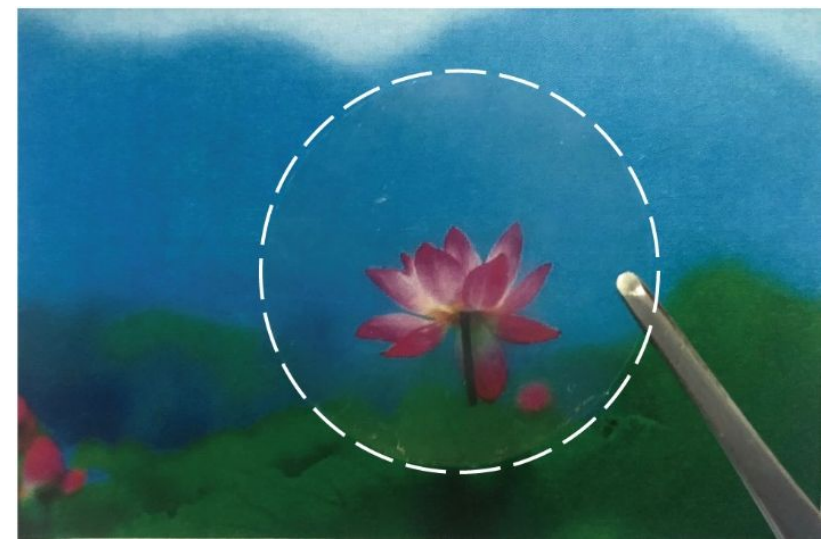

Figure S6. Transparent nanopaper. 


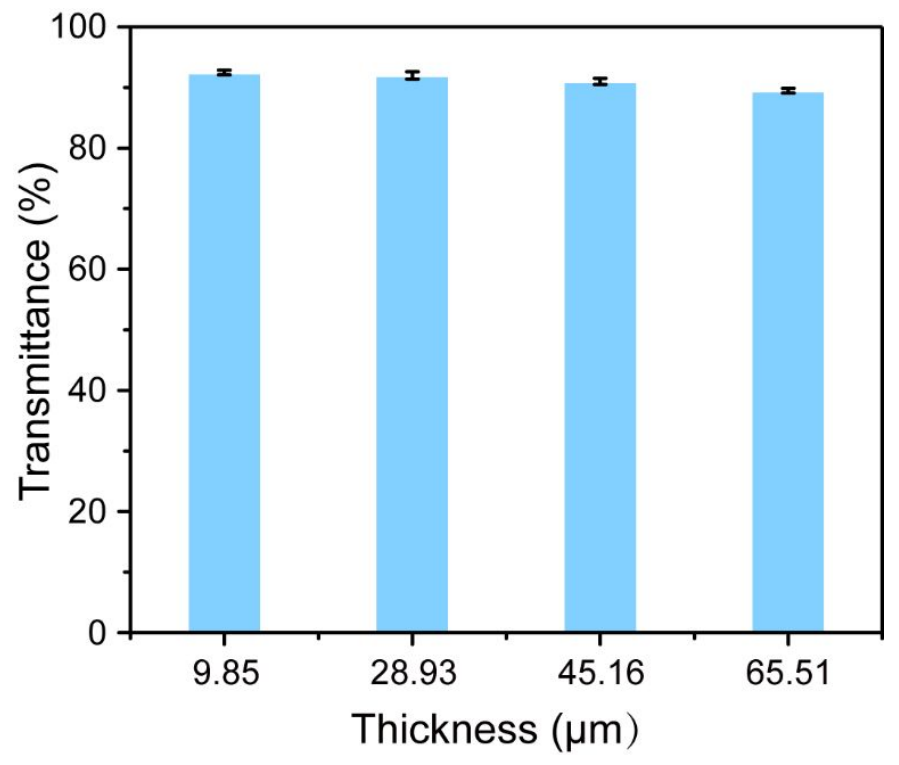

Figure S7. The transmittance of transparent paper with a varying thickness at $550 \mathrm{~nm}$.
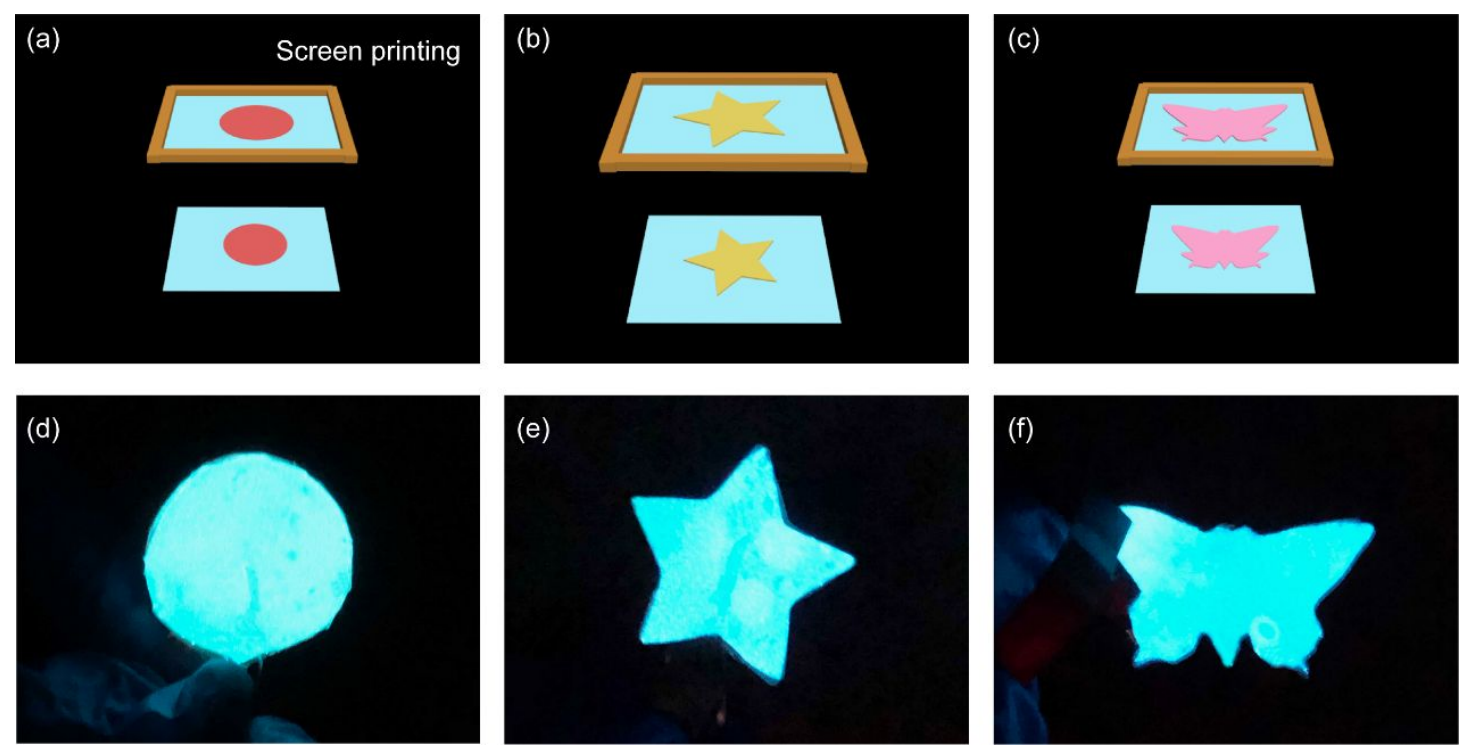

Figure S8. Patternable printing of TCNP and personalized display of TCNPbased electroluminescent devices. PDES was used as conductive ink to print the (a) circle, (b) star and (c) butterfly on nanopaper by screen printing, and the electroluminescent devices (d-f) were assembled correspondingly. 


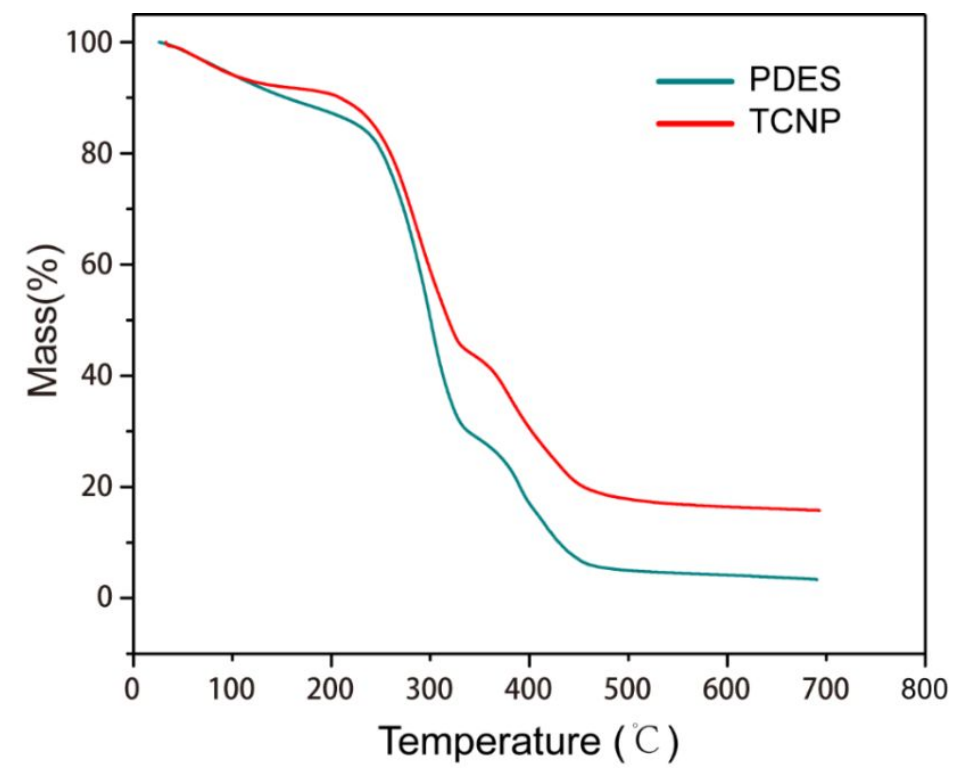

Figure S9. Thermal gravimetric analysis (TGA) of the PDES and the TCNP.

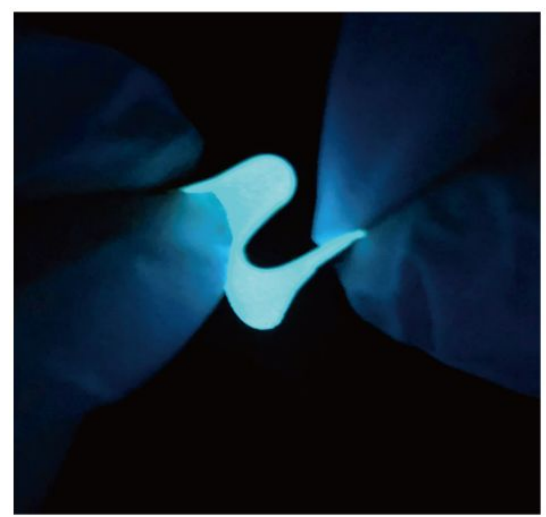

Pristine

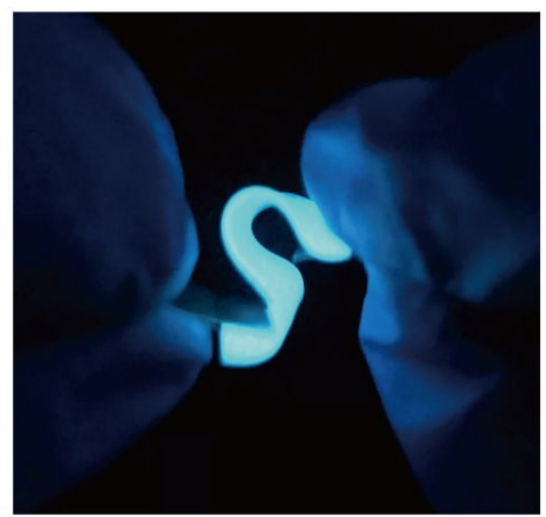

After 180 days

Figure S10. Long-term electrical robustness of TCNP. The assembled electroluminescent devices even remained high brightness after 180 days. 
Table S1. Average thickness of nanopaper with different gram weight.

\begin{tabular}{lcccc}
\hline Gram weight of nanopaper $\left(\mathrm{g} / \mathbf{m}^{\mathbf{2}}\right)$ & $\mathbf{2 0}$ & $\mathbf{4 0}$ & $\mathbf{6 0}$ & $\mathbf{8 0}$ \\
\hline Average thickness of nanopaper $(\mu \mathrm{m})$ & 9.85 & 28.93 & 45.16 & 65.51 \\
\hline Average thickness of TCNP $(\mu \mathrm{m})$ & 25.05 & 49.56 & 67.25 & 85.63 \\
\begin{tabular}{l} 
coating amount of PDES was $\left.60 \mathrm{~g} / \mathrm{m}^{2}\right)$ \\
\hline
\end{tabular}
\end{tabular}

Table S2. The weight of the nanopaper and the TCNP.

\begin{tabular}{|c|c|c|c|c|c|}
\hline & Gram weight of nanopaper $\left(\mathrm{g} / \mathrm{m}^{2}\right)$ & 20 & 40 & 60 & 80 \\
\hline \multirow{5}{*}{$\begin{array}{l}\text { Weight } \\
\text { (g) }\end{array}$} & Raw nanopaper & 0.0261 & 0.0695 & 0.0769 & 0.1054 \\
\hline & $\begin{array}{c}\text { TCNP } \\
\text { (coating amount of PDES was } 40 \mathrm{~g} / \mathrm{m}^{2} \text { ) }\end{array}$ & 0.0714 & 0.0948 & 0.1157 & 0.1351 \\
\hline & $\begin{array}{c}\text { TCNP } \\
\text { (coating amount of PDES was } 50 \mathrm{~g} / \mathrm{m}^{2} \text { ) }\end{array}$ & 0.0869 & 0.1216 & 0.1397 & 0.1582 \\
\hline & $\begin{array}{c}\text { TCNP } \\
\text { (coating amount of PDES was } 60 \mathrm{~g} / \mathrm{m}^{2} \text { ) }\end{array}$ & 0.1014 & 0.1452 & 0.1523 & 0.1808 \\
\hline & $\begin{array}{c}\text { TCNP } \\
\text { (coating amount of PDES was } 70 \mathrm{~g} / \mathrm{m}^{2} \text { ) }\end{array}$ & 0.1241 & 0.1576 & 0.1648 & 0.1933 \\
\hline
\end{tabular}

Table S3. The addition amounts of AgNWs, PEDOT:PSS, CNT and graphene.

\begin{tabular}{c|c|c|c|c}
\hline Conducting fillers & AgNWs & PEDOT:PSS & CNT & Graphene \\
\hline The addition amounts & $0.014 \mathrm{~g}$ & $0.023 \mathrm{~g}$ & $0.008 \mathrm{~g}$ & $0.009 \mathrm{~g}$ \\
\hline
\end{tabular}

The conductivity was calculated by the formula $\mathrm{S} 1$,

$$
C=R * S / L
$$

where $\mathrm{C}$ represented the conductivity, $\mathrm{R}$ reparented the resistance, $\mathrm{S}$ represented contacted area of the TCNP and the coppers, L represented thickness of the TCNP. 
Table S4. Preparation and transparency of transparent conducting nanopaper with common conductive materials.

\section{Transmittance}

Conductive

fillers
Preparation Process (at $550 \mathrm{~nm})$

\begin{tabular}{cc}
\hline Original & Conductive \\
nanopaper & nanopaper
\end{tabular}

\section{References}

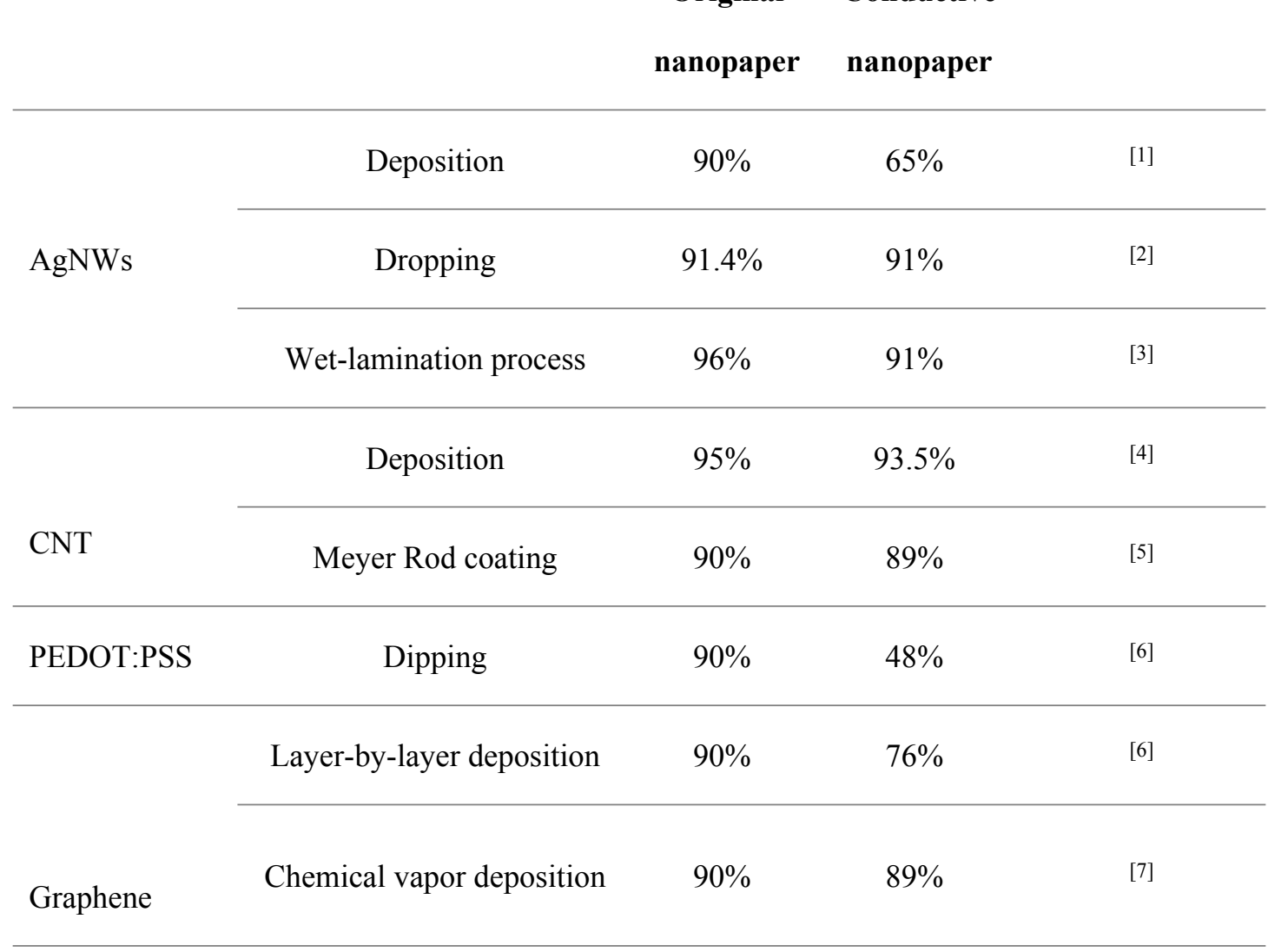

\begin{tabular}{lllll} 
Poly(PDES) & Screen printing & $92 \%$ & $94.5 \%$ & This work \\
\hline
\end{tabular}

\section{References:}

(1) Hu, L.; Zheng, G.; Yao, J.; Liu, N.; Weil, B.; Eskilsson, M.; Karabulut, E.; Ruan, Z.; Fan, S.; Bloking, J., Transparent and Conductive Paper from Nanocellulose Fibers. Energy Environ.

Sci. 2013, 6 (2), 513-518, DOI: 10.1039/c2ee23635d.

(2) Nogi, M.; Karakawa, M.; Komoda, N.; Yagyu, H.; Nge, T., Transparent Conductive Nanofiber Paper for Foldable Solar Cells. Sci. Rep. 2015, 5, 17254 (1-7), DOI: 
10.1038/srep17254.

(3) Preston, C.; Fang, Z.; Murray, J.; Zhu, H.; Dai, J.; Munday, J.; Hu, L., Silver Nanowire Transparent Conducting Paper-based Electrode with High Optical Haze. J. Mater. Chem. C 2014, 2 (7), 1248-1254, DOI: 10.1039/c3tc31726a.

(4) Zhong, J.; Zhu, H.; Zhong, Q.; Dai, j.; Li, W.; Jiang, S.; Yao, Y.; Henderson, D.; Hu, Q.;

Hu, L., Self-Powered Human Interactive Transparent Nanopaper Systems. ACS Nano 2015, 9 (7), 7399-7406, DOI: 10.1021/acsnano.5b02414.

(5) Huang, J.; Zhu, H.; Chen, Y.; Preston, C.; Rohrbach, K.; Cumings, J.; Hu, L., Highly Transparent and Flexible Nanopaper Transistors. ACS Nano 2013, 7 (3), 2106-2113, DOI: $10.1021 / \mathrm{nn} 304407 \mathrm{r}$.

(6) Wang, X.; Gao, K.; Shao, Z.; Peng, X.; Wu, X.; Wang, F., Layer-by-Layer Assembled Hybrid Multilayer Thin Film Electrodes Based on Transparent Cellulose Nanofibers Paper for Flexible Supercapacitors Applications. J. Power Sources 2014, 249, 148-155, DOI: 10.1016/j.jpowsour.2013.09.130.

(7) Zhu, H.; Fang, Z.; Wang, Z.; Dai, J.; Yao, Y.; Shen, F.; Preston, C.; Wu, W.; Peng, P.; Jang, N.; Yu, Q.; Yu, Z.; Hu, L., Extreme Light Management in Mesoporous Wood Cellulose Paper for Optoelectronics. ACS Nano 2016, 10 (1), 1369-1377, DOI: 10.1021/acsnano.5b06781. 